Numerous attempts, only very partially successful, have been made to establish similar definite relations between solar and terrestrial atmospheric variations. The South Kensington observatory has done much valuable work in this direction. It is, however, doubtful whether the results obtained by any of the investigators in this branch are generally accepted.

The reasons for this very partial success are almost self-evident, and are due to the complexity of the problems presented by the movements of the atmosphere, more especially as modified by the presence of very varying amounts of aqueous vapour, the result of the processes of evaporation and condensation. The effects of the solar variation on the earth's atmosphere are, in fact, distributed and manifested in very varying proportion between the different elements of observation, and the direct effect of a solar variation on one element may be followed by an opposite effect due to variation of another element, so that the final result may be opposite in character to the initial effect. Thus an increase of solar radiant energy would, if there were no increase of aqueous vapour amount, cloud or air movement, undoubtedly increase pressure and temperature. If these changes, however, give rise to increased vertical and horizontal movement, it is possible that as a later result pressure probably, and temperature possibly, might both be decreased below their original or normal level, and hence that the observed change might be. the opposite to that of the direct effect of the original variation. Also there is another source of difficulty in this branch of the inquiry, due to the fact that in the case of some of the elements of observation a positive variation over a considerable area of the earth's surface must necessarily be accompanied with a negative variation of corresponding amount in some other region as part and parcel of the total change. The changes in these elements, taken over the earth's surface, must either be completely compensatory, as is probably the case for pressure, or partially compensatory, as is undoubtedly the case for rainfall.

It is also necessary to bear in mind that the instrumental appliances for magnetical and meteorological observations are of very different orders of exactness. Magnetic instruments, more especially those for continuous autographic registration, are of great delicacy. Meteorological instruments are, on the other hand, much less delicate, and the most important of all from certain points of view, viz. the instruments for registering the direction and rate of air movement, are especially coarse, and their individual observations are necessarily affected with large errors.

The problem of the relations between solar and terrestrial meteorological variations is hence contplicated and difficult. It evidently requires for its complete solution the collection and coordination of data for the whole of the earth's surface, and the careful employment of statistical methods regulated by thorough knowledge of the physics of the atmosphere.

The difficulties of the problem are great, and explain the comparative want of success of investigators hitherto. It is, however, certain from theoretical considerations that there are definite relations, and that their determination is of great importance, equally from the scientific and the utilitarian point of view.

The observational data for a more systematic investigation are now considered by many to be sufficient, if collected, compared, and discussed as a whole, to promise more satisfactory and valid conclusions than have hitherto been obtained, and NO. 1863 , VOL. 72$]$ perhaps a first approximate solution. This opinion found expression fully at the meeting of the British Association at Southport in I903. Sir Norman Lockyer, director of the Solar Physics Observatory, South Kensington, read a report giving a summary of the results of previous investigations in "Simultaneous Solar and Terrestrial Changes " to Section A of the British Association. The members of the International Meteorological Committee present at the meeting joined in the discussion, and it was decided that the time had arrived for joint and concerted action. A commission to act as a subcommittee of the International Meteorological Committee was formed to discuss meteorological observations from the point of view of their connection with magnetism and solar physics. The commission held several meetings at Cambridge in roo4 during the British Association week. Several additional members were added to the commission, which now includes the names of the leading authorities in the three associated branches of science.

The chief work of the commission at Cambridge was to lay down principles for the selection of the data required for comparison, and to arrange for the choice of stations and observatories from which it would be desirable to obtain data prior to entering into communication with the various organisations that it would be necessary to ask for assistance in the collection of data.

It has been arranged that a meeting of the commission shall be held in connection with the meeting of the International Meteorological Committee at Innsbruck in September. A number of important matters will there be considered. Amongst these are the final selection of magnetic and meteorological observatories from which data are to be collected, the mode of publication of the data received by the commission, and probably, also, of the methods to be employed in the work of comparison and discussion of the data. Hofrath Prof. Julius Hann has suggested for consideration a method of determining the variation of temperature during a sun-spot period. This will, it is hoped, lead to an interesting discussion on the methods of investigation most suited and appropriate for the determination of the relations between solar and terrestrial phenomena.

\section{THE PROPOSED COLLEGE OF APPLIED SCIENCE.}

THE appearance of the preliminary report of the Departmental Committee on the Royal College of Science and Royal School of Mines, which was published in our issue of last week, brings us an important step nearer the realisation of an object after which men of science have long striven; the provision, that is, of a great metropolitan college-liberally endowed, handsomely housed, adequately equipped, and generously staffed-designed amply to supply that higher technical instruction for which there has been little provision hitherto, but upon which our well-being as a commercial and manufacturing nation ultimately depends.

The report shows that the committee has been engaged wisely in determining what precisely the existing facilities for instruction in applied science are, and in gathering the information necessary to decide what the new college should supply in addition to these, so as to place London, as the centre of the Empire, in a condition to compare educationally with Berlin, for example, or with many great American cities. It is unnecessary here to recapitulate the recommendations of the committee, but the special wisdom of 
one or two of its conclusions cannot be insisted upon too earnestly or too often.

The new institution must be in no sense parochial, nor must it be allowed to become merely metropolitan. From the beginning the design must be to give the college an Imperial character, and every means must be taken to encourage young men possessed of the necessary qualifications, in whatever part of the Empire they may be, to attend its courses and avail themselves of the means offered by it of becoming familiar with recent advances in technology and with any branch of applied science in its highest form.

The new institution must not be allowed to become merely another technical college on a larger scale-of technical institutes we have many already. The "duly qualified students" referred to by the committee should have already received collegiate training, and have taken a degree. To quote the report:"Admission to these higher courses should be restricted to duly qualified students who, it is hoped, would be attracted from all parts of the Empire." The public must be taught to estimate the success of the new institution, not by the number of its roll-call, but by the number of expert engineers of all kinds, of original technical chemists, of machine designers, and so on, who are trained within its portals.

But besides being able to supply the future manufacturer with the very latest results from the research laboratories of workers outside its walls, the new institution, if it is to be really successful, must itself be an active centre of research. As the report says :-.." It is of the first importance that there should be no divorce between teaching and research in technology on the one hand and in pure science on the other," and the new college must be as notable for its success in research in technology as for the ability possessed by its staff to acquaint the student with the findings of recent scientific work. Unless from the beginning the student feels he is under the influence of professors who are not only familiar with all the conditions of actual manufacture in its most successful form, but who are responsible also for the improvements in technical processes which win success, the institution will neither do the work expected of it nor win the confidence of our manufacturing magnates and mer. chant princes. Only that science-whether pure or applied-really lives which grows continually, and such growth without patient research is impossible. The new institution must above all things be the growing point of our national system of technical instruction.

To fulfil these two functions--on which the report rightly lays very great emphasis - the staff of the Imperial college must be both numerous and the best available. In other words, the institution must of necessity be a costly one, judged, that is, from the standard adopted previously in this country for estimating educational expenses. But if properly selected such a staff will very soon show, by the results accomplished, that generous expenditure on higher education is a remunerative form of national expenditure. It is gratifying to find from the report that there is every prospect that a sufficient revenue will be eventually forthcoming, in the provision of which funds the State will take its part. We learn from the Times that the Government has decided to allocate 20,00ol. a year to the college out of the Treasury subsidy for the maintenance of the Royal College of Science and the Royal School of Mines, and that an intimation to this effect has been made by the Chancellor of the Exchequer to Mr. Haldane, the chairman of the Departmental Committee.

There is every reason to hope that London will ere long have at South Kensington a college of applied science which will be as much admired as the similar institution at Charlottenburg, and prove as useful to the industries of this country as the Berlin college has to those of Germany.

\section{NOTES.}

As the new buildings of the University of Sheffield were opened by the King at the time the present issue of Nature was being prepared for press, we cannot do more than record the fact, reserving a description of the buildings and an account of the opening ceremony for a subsequent number.

THE annual meeting of the Imperial Cancer Research Fund was held on July 5 at Marlborough House, the Prince of Wales presiding. Sir William Church moved the adoption of the secretary's, superintendent's, and treasurer's reports, which was seconded by Mr. Tweedy. Mr. Henry Morris moved that the best thanks of the meeting be given to His Royal Highness for presiding, which was carried with acclamation. The Prince of Wales in reply alluded to the researches which had been carried out in the laboratories of the fund, and expressed his satisfaction that the committee had again secured the services of Sir William Church as chairman of the executive committee.

THE summer show of the Royal Horticultural Society was opened on Tuesday last, and will remain open until this evening. It is being held for the first time in the grounds of Chelsea Hospital. The society appears to be in a very flourishing condition, more than rooo new fellows having been added within the last few months.

THE Albert medal of the Society of Arts for 1905 was, on Wednesday, July 5, at Marlborough House, presented by the Prince of Wales, as president of the society, to Lord Rayleigh " in recognition of the influence which his researches, directed to the increase of scientific knowledge, have had upon industrial progress, by facilitating, amongst other scientific applications, the provision of accurate electrical standards, the production of improved lenses, and the development of apparatus for sound signalling at sea."

THE French Association for the Advancement of Science will this year meet at Cherbourg. The session will extend from August 3 to 10.

THE summer meeting of the Institution of Naval Architects will take place on July 19, 20, and 21 in the hall of the Society of Arts. The following papers will be read and discussed:- "Tactics and Strategy at the Time of Trafalgar," by Admiral Sir Cyprian Bridge, G.C.B.; "The Ships of the Royal Navy as they Existed at the Time of Trafalgar," by 'Sir Philip Watts, K.C.B., F.R.S., vice-president; "The Classification of Merchant Shipping, illustrated by a Short History of Lloyd's Register," by H. J. Cornish; "Experiments with Models of Constant Length and Form of Cross Sections, but with varying Breadths and Draughts," by Lieut.-Col. B. Rota ; "Experiments on the Effect of Depth of Water on Speed, having Special Reference to Destroyers recently Built," by H. Yarrow; "Deductions from Recent and Former Experiments on the Influence of the Depth of Water on Speed," by W. W. Marriner; "The Failure of some large Boiler Plates," by J. T. Milton; and "A Comparison of the Performances of Turbines and Reciprocating Engines in the Midland Railway Company's Steamers," by W. Gray.

NO. I $86_{3}$, vOL. 72$]$ 